\title{
Analysis of the practice of establishing the size of regional coefficients to the wages of workers in areas with unfavourable natural and climatic conditions and proposals for its improvement
}

\author{
Irina Omelchenko ${ }^{1}$, Oleg Dozortzev ${ }^{1}$, and Marina Danilina ${ }^{1,2,3, *}$ \\ ${ }^{1}$ Research Institute VNII of Labor, Ministry of Labour of Russia, 105064 Moscow, Russia \\ ${ }^{2}$ Finance University under the Government of the Russian Federation, 125993 Moscow, Russia \\ ${ }^{3}$ Russian Economic University, 117997 Moscow, Russia
}

\begin{abstract}
District coefficients are designed to compensate for differences in the cost of living of the population in the northern and eastern regions compared to the central and southern regions due to the unequal needs of the population. On the basis of the content analysis of the legislation the authors showed that in order to improve the legislation on regional coefficients to the wages of workers in areas with unfavorable natural and climatic conditions for the population, it is necessary to prepare new methodological approaches to determining the size of regional coefficients on the basis of the minimum (recovery) budget or the minimum consumer budget and to introduce the practice of establishing uniform regional coefficients for the wages of all employees of enterprises, organizations and institutions in the constituent entity of the Russian Federation or in municipal districts and urban districts within the constituent entity of the Russian Federation.
\end{abstract}

\section{Introduction}

In Russia, in recent years, a lot of work has been done to incorporate the normative legal acts of the USSR and the RSFSR or their individual provisions into the legislation of the Russian Federation, including legal acts relating to the issues of regional regulation of wages, in particular, the currently applied regional coefficients to the wages of workers. in the northern, arctic and other regions of Russia with special natural and climatic conditions. The work on incorporation is based on the legal documents published by the Russian Federation: the order of the President of the Russian Federation of March 18, 2011 No. 158-rp "On the organization of work on the incorporation of legal acts of the USSR and the RSFSR or their individual provisions into the legislation of the Russian Federation and (or) on the recognition of these acts invalid on the territory of the Russian Federation"; Order of the Ministry of Justice of the Russian Federation of 03/06/2013 No. 28 "On approval of the Action Plan for the incorporation of legal acts of the USSR and the RSFSR or their individual provisions into the legislation of the Russian Federation and (or) on the recognition of these acts as invalid in

* Corresponding author: marinadanilina@yandex.ru 
the territory of the Russian Federation for 2013 and the List of legal acts of the USSR and the RSFSR or their individual provisions subject to incorporation into the legislation of the Russian Federation in 2013"; Order of the Ministry of Labor and Social Protection of the Russian Federation dated 01.11.2013 No. 654 "On the plan of measures for the incorporation of legal acts of the USSR and the RSFSR or their individual provisions into the legislation of the Russian Federation for 2013". In the future, the need to work on incorporation was reflected in the order of the Ministry of Justice of the Russian Federation of March 10, 2016 No. 60 "On approval of the Action Plan for the incorporation of legal acts of the USSR and the RSFSR or their individual provisions into the legislation of the Russian Federation and (or) on the recognition of these acts as invalid on the territory of the Russian Federation for 2016 and the List of legal acts of the USSR and the RSFSR or their individual provisions subject to incorporation into the legislation of the Russian Federation in 2016 ".

The issues of regional regulation of wages and, accordingly, regulatory legal acts regulating labor relations in areas with special climatic conditions have not lost their significance and relevance at the present time. The relevance of the ongoing study of the legal regulation of labor relations in the northern and Arctic regions of Russia is currently due, along with the above, and in connection with the updating of legislation, in particular, the adoption of new laws on the Arctic, on territories of advanced socio-economic development.

The decree of the President of the Russian Federation dated 05.03.2020 No. 164 "On the foundations of state policy in the Arctic zone until 2035" defines Russia's national priorities in this region. Among them, ensuring a high quality of life and well-being of the population of the Arctic and the development of its resource base, as well as the development of the Northern Sea Route, and the federal law of 13.07.2020 No. 193-FZ "On state support for entrepreneurial activities in the Arctic zone of the Russian Federation", the issues of financial support for the creation (modernization) of infrastructure facilities in the Arctic zone, the implementation of entrepreneurial activities in the Arctic zone.

In the decree of the President of the Russian Federation of June 26, 2020 No. 427 "On measures for the socio-economic development of the Far East", the Government of the Russian Federation is proposed for the period until 2024: to ensure that the average Russian growth rates of the population's quality of life indicators are exceeded, including in the following areas: an increase in life expectancy by at least five years, a decrease in the mortality rate of the working-age population by at least $35 \%$, an increase in the annual volume of housing construction by 1.6 times; exceeding the average Russian growth rates of economic development indicators, including through the creation of at least 200 enterprises in the territories of advanced social and economic development, as well as at least 30 thousand jobs.

In the work that we carried out in 2020, we analyzed 32 resolutions of the USSR State Committee for Labor and the All-Union Central Council of Trade Unions Secretariat for 1959-1974. and 4 decrees for 1980-1988, most of which should be recognized as valid, but subject to incorporation. However, the incorporation did not solve the problem of eliminating the multiplicity of existing regional coefficients in territories with the same natural and climatic conditions.

In order for incorporation to be effective, it is necessary to improve the system for establishing the size of regional coefficients based on equalizing the conditions for the reproduction of the labor force across regions, i.e. compensate for the differences in the cost of living of the population in the northern and eastern regions in comparison with the regions with the most favorable living conditions for the population.

At present, regional coefficients for wages are applied in about $70 \%$ of the territory of the Russian Federation, where, as of 01.01 .2020 , 36.1\% of the population of Russia lived, including in the regions of the Far North, equated localities, in the southern regions of Eastern Siberia and the Far East, where regional coefficients and percentage allowances for work 
experience are applied, $13.3 \%$ of the population; in Western Siberia, the Urals, in some constituent entities of the Russian Federation, the Volga Federal District and the Vologda Oblast $-22.8 \%$. This requires careful attention to the establishment of the size of the regional coefficients or their change.

Regional coefficients were introduced into the practice of organizing wages in the USSR after the publication of the decree of the Central Committee of the CPSU, the Council of Ministers of the USSR and the All-Union Central Council of Trade Unions of 19.09.1959, No. 1120 in areas "... with severe climatic conditions, insufficiently provided with labor force ...". In the USSR, regional coefficients to the wages of workers were established mainly according to the sectoral principle (oil and gas industry, construction, mechanical engineering, heavy industry, forestry, woodworking and pulp and paper, transport (river, sea, aviation, etc.), further light and food industries, and then installed centrally for workers in the non-production sector by the Decree of the State Committee for Labor of the USSR and the Presidium of the All-Union Central Council of Trade Unions of 04.09.1964, No. 380 / P18. At that time, regional coefficients were introduced mainly in the regions of the Far North and areas equated to them, and their sizes were established depending on the severity of natural and climatic conditions, the remoteness of territories and the development of the area. Subsequently, regional coefficients to wages were introduced in the European North, the Urals, in the southern regions of Siberia and the Far East.

In Russia, after the publication of the Law of the Russian Federation of February 19, 1993, No. 4520-1, the sizes of regional coefficients began to be established on a territorial basis, i.e. a single size of the regional coefficient to the wages of all workers and employees of the constituent entity of the Russian Federation (Novosibirsk region and the Republic of Khakassia and Altai), or municipal districts and urban districts within the constituent entity of the Russian Federation (Republic of Karelia, Tomsk and Tyumen regions, the Republic of Tyva).

\section{Materials and methods}

It should be noted that in the regulatory legal acts of the USSR, which continue to operate on the territory of the Russian Federation, the abolished bodies of state power and administration are still mentioned, no changes have been made: the concepts and terms used in the legislation of the Russian Federation, the reorganization of the administrative territorial division of the Russian Federation, in the names of the subjects of the Russian Federation, their unification or separation into independent subjects of the Russian Federation, in the transformation of districts into municipalities, cities with a territory that is under the administrative subordination of the city Council of People's Deputies, into urban districts, etc. Of the USSR in accordance with the legislation of the Russian Federation is becoming more and more significant and relevant.

Incorporation, as a special form of bringing the normative legal acts of the former USSR in accordance with the legislation of the Russian Federation, is, in principle, a constant activity of state and other bodies in order to maintain legislation in its current state, ensure its availability, and provide the widest range of subjects with reliable information about laws and other normative legal acts in their current edition.

In the legal literature, incorporation is a processing of legislation that does not introduce new content into it. This is an external systematic processing of existing legalizations, which consists in the fact that the text of the main regulatory legal act introduces regulatory legal provisions from subsequent official acts, which amend and supplement them, as well as remove individual prescriptions, clauses, paragraphs that have become invalid (outdated, in fact not valid), while the content of legal regulation does not essentially change. It is this type of incorporation that is used in this work. 
In accordance with the above, the VNII Labor during 2015-2019 analyzed the regulatory legal acts of the USSR and the RSFSR on issues of regional regulation subject to incorporation into the legislation of the Russian Federation or to recognize them as invalid on the territory of the Russian Federation. The analysis of the normative legal acts of the former USSR concerned the introduction into practice of the size of regional coefficients (including increased ones) to the wages of workers of specific enterprises, organizations and institutions located in the regions of the Far North and equivalent areas, including the Arctic, based on the results of which proposals were prepared on the recognition of some regulatory legal acts as invalid, other acts or their individual provisions subject to incorporation into the legislation of the Russian Federation.

In 2019, work on the preparation of scientifically based proposals for the incorporation of regulatory legal acts concerning the current size of regional coefficients to the wages of workers was continued and concerned, in particular, the issues of establishing sectoral regional coefficients in the northern and eastern regions, including the Arctic. The results of the study made it possible to recognize that all analyzed sectoral regulatory legal acts of the former USSR by type of economic activity, due to legislative inaccuracies, contradictions, changes, are subject to incorporation, and some of their provisions are recognized as invalid due to the adoption of resolutions of the Government of the Russian Federation, the Constitution of the Russian Federation, and other regulatory documents, including regional legislation. At the same time, an even large array of normative acts in the field of regional regulation requires research to improve them.

In 2020, work continued on the study and preparation of scientifically grounded proposals for the incorporation of regulatory legal acts of the system of operating regional coefficients to the wages of workers in the northern, Arctic and other regions of Russia with special natural and climatic conditions.

The purpose of this work is to analyze the regulatory legal acts of the former USSR on establishing the size of regional coefficients (including increased ones) to the wages of workers by type of economic activity located in the northern, arctic and other regions of Russia with special natural and climatic conditions and on its basis, the preparation of proposals for their incorporation, i.e. to bring them into line with the legislation of the Russian Federation.

To achieve this goal, the following research tasks were completed:

- the selection and consideration of the regulatory legal acts of the former USSR for 19591988, concerning the establishment of the size of regional coefficients (including increased) by types of economic activity, in order to identify the prerequisites for incorporation into the legislation of the Russian Federation in accordance with the recommendations described in section 6.2. The General Agreement for 2018-2020;

- analyzed the regulatory legal acts of the former USSR on the establishment of the size of regional coefficients (including increased) by types of economic activity;

- a comparative analysis of the normative legal acts of the former Union of the USSR on the establishment of the sectoral sizes of regional coefficients, including increased ones, to the wages of employees of enterprises and organizations of the northern and eastern regions of Russia, including the Arctic, and subsequent regulatory legal acts, adopted later, concerning changes in the established regional coefficients, reorganization of administrative - territorial division, abolition of settlements, etc.;

- theoretical approaches to determining the size of regional coefficients to the wages of workers in the northern and eastern regions, including the Arctic, have been investigated;

- scientifically grounded proposals have been prepared for the incorporation of the normative legal acts of the former USSR into the legislation of the Russian Federation or the recognition as invalid in whole or in part of some of their provisions (points) on the establishment of the 
current size of regional coefficients (including increased ones) by types of economic activity in , arctic and other regions of Russia with special climatic conditions.

The scientific novelty of the study is that it carried out a constructive analysis of the current legislation of the former USSR on the application of the sizes of regional coefficients in the northern, eastern and arctic regions of Russia, in the development of which proposals for the incorporation of normative legal acts of the former USSR into the legislation of the Russian Federation (or their recognition as invalid), and it was also proposed to prepare recommendations for determining the size of regional coefficients in the northern, arctic and other regions with unfavorable natural and climatic conditions, taking into account the zoning of the territory of Russia by natural, climatic and other factors.

The materials contained in the work can be used by the Ministry of Labor of Russia in the preparation of proposals subject to incorporation of the normative legal acts of the former USSR, regulating the issues of remuneration in the northern, arctic and other regions of Russia with special climatic conditions into the legislation of the Russian Federation, as well as in the preparation of new guidelines for determining the size of regional coefficients to the wages of workers in the northern and eastern regions, including the Arctic, and in the Urals, Volga and southern regions of the Siberian federal districts. The proposals provided for in the work will contribute to the implementation of the "Strategy for the spatial development of the Russian Federation for the period up to 2025", approved by the order of the Government of the Russian Federation of 13.02.2019, No. 207-r, in which great attention is paid to improving the socio-economic development of the northern and eastern regions, including the Arctic.

District coefficients are designed to compensate for differences in the cost of living of the population in the northern and eastern regions compared to the central and southern regions due to the unequal needs of the population for food, clothing, footwear, household items, costs of housing and communal services and transport services, as well as different levels of prices for goods and tariffs for paid services.

In addition to equalizing the differences in the cost of living of the population, they performed a stimulating function to attract workers to the northern and eastern regions, especially if they were set at an increased rate. For example, for the period of construction of the Baikal-Amur Mainline (BAM), a regional coefficient of 1.50 was set to the wages of workers instead of 1.30 established for workers of other enterprises, organizations and institutions in this region.

In the Labor Research Institute of the USSR State Committee for Labor, as well as in other scientific institutions of the USSR and the RSFSR State Planning Committee, the size of the regional coefficients was determined based on the differences in the cost of the minimum consumer budget of a man of working age or a family of 4 people in the compared and base regions. At the same time, the Institute of Geography of the Russian Academy of Sciences preliminarily carried out zoning of the territory of Russia (formerly the USSR) according to zones of favorable living conditions for the population (5 zones).

Employees of the Research Institute of Labor periodically performed calculations of territorial differences in the cost of living in the northern and eastern regions in comparison with the average for the Russian Federation and regions with the most favorable natural and climatic conditions to determine the size of regional coefficients based on specially prepared methodological approaches to substantiating sets of consumer baskets for men employed in moderate labor, in structure close to the set of the minimum consumer budget of a man of working age.

Preliminary, together with the Institute of Geography of the Russian Academy of Sciences, the zoning of the territory of Russia by natural and climatic zones was carried out. Methodological approaches to determining the size of regional coefficients, prepared by a team of scientists (Institute of Geography RAS, Institute of Nutrition RAS, INP RAS, 
Research Institute of Labor and others), are published in the collective monograph "Zoning of the North of Russia: Scientific Approaches - Moscow: Publishing House of RAGS, 2010 ". Currently, approximate territorial differences in the cost of living of the population can be determined on the basis of Rosstat data on differences in the subsistence minimum of the working-age population, since they partially take into account the differences in the cost of living of the population in the constituent entities of the Russian Federation. For example, in the 2 nd quarter of 2020, the differences in the size of the subsistence minimum of the ablebodied population in comparison with their value in Russia and especially compared with the constituent entities of the Russian Federation with favorable natural and climatic conditions are higher than the current sizes of regional coefficients in the Murmansk region, Nenets, Yamalo-Nenets and Chukotka Autonomous Districts, Magadan Region and Kamchatka Territory.

In order to objectively assess territorial differences in the cost of living of the population and determine the size of regional coefficients to wages of workers in regions with unfavorable natural and climatic conditions, including the Arctic, it is advisable, on the basis of regulatory documents of research institutes or ministries, to prepare guidelines by determining the minimum (recovery) budget for a worker engaged in moderate labor in normal production conditions, or families of 4 people with 2 workers, including the costs of medical care, education for children, spending on recreation, purchase of housing, which are currently not included in the structure of the consumer basket. For comparison, it is advisable to carry out similar calculations in areas with the most favorable natural and climatic conditions, which will allow us to determine the current size of regional coefficients to the wages of workers in the northern and eastern regions, as well as in the Siberian, Ural and Volga federal districts and the Vologda region.

\section{Results and discussions}

In the General Agreement for 2018-2020. in the second part of clause 2.2 it is proposed "to hold consultations of the parties and, if necessary, make proposals on the development of a methodology for calculating the value of the minimum (recovery) consumer budget of the able-bodied working population as a whole in the Russian Federation and in the constituent entities of the Russian Federation, taking into account the possible differentiation of budgets depending on from the goals and objectives of their application". In our opinion, it is advisable to use this budget to determine the differences in the cost of living by region and the size of regional coefficients.

It should be noted that there is a constant migration outflow of the population from the northern and eastern regions, including the Arctic, with a very low natural increase. In 2019, in the Far Eastern Federal District, the migration outflow of the population amounted to 11,731 people, the Chukotka Autonomous District had a positive increase of 546 people, the Republic of Buryatia - 999 people and Primorsky Krai - 61 people. At the same time, the Murmansk region, the Nenets and Yamalo-Nenets autonomous districts, which are completely part of the Arctic, had a negative migration population growth in 2019. In the first half of 2020, the migration growth of the population in the Far Eastern Federal District was negative; only the Republic of Sakha (Yakutia) and the Kamchatka Territory, which are part of the Federal District, as well as oil and gas producing autonomous districts, had a positive increase. Negative migration growth was observed in the Republics of Karelia and Komi, in the Murmansk region, in most of the subjects of the Russian Federation in the Far East. 


\section{Conclusion}

This paper presents the final stage of work on the incorporation of the normative legal acts of the USSR State Committee for Labor and the All-Union Central Council of Trade Unions Secretariat on the application of the current regional coefficients to wages, including increased ones, into the legislation of the Russian Federation. The paper analyzes legislative acts on establishing the size of regional coefficients to the wages of workers in the manufacturing sector (oil and gas industry, construction and repair and construction organizations, forestry, electricity, peat, woodworking, agriculture, light, food and others), employees of organizations and institutions (systems of the State Bank of the USSR, Stroybank of the USSR and financial authorities, radio broadcasting and television, design and survey organizations, computing centers and others), individual enterprises of the machine-building and metalworking industries, adopted in 1959-1974. and on the basis of which scientifically grounded proposals were prepared for their incorporation into the legislation of the Russian Federation. For individual constituent entities of the Russian Federation and types of economic activity in 1981-1988. 4 resolutions of the State Committee for Labor and the Secretariat of the All-Union Central Council of Trade Unions were adopted, which should be recognized as valid.

The analysis of the sectoral regulatory legal acts of the former USSR on the issues of establishing the size of regional coefficients for the constituent entities of the Russian Federation, as well as individual regions and cities within them, carried out in this work, showed that the content of many provisions of regulatory legal acts creates objective grounds for their incorporation into the legislation of the Russian Federation, since the changes made do not change their legal content.

Based on the results of the analysis of the decisions of the USSR State Committee for Labor and the All-Union Central Council of Trade Unions, the reasons for the need for incorporation were identified. These include:

- the publication of the decree of the Council of Ministers of the USSR and the All-Union Central Council of Trade Unions of the USSR and the All-Union Central Council of Trade Unions of 08/01/1989 No. 601 "On the establishment of a uniform size of regional coefficients to wages for all employees in the Kemerovo region" and the publication of a number of decrees of the Government of the Russian Federation in the Novosibirsk region, the Republics of Altai and Khakassia, separate municipal districts and urban districts in the Republics of Karelia and Tyva;

- changes in the federal structure of the Russian Federation;

- change of administrative - territorial division;

- changing the names of republics, territories, regions, national districts;

- withdrawal of the union republics of the former USSR (Kazakhstan, Uzbekistan, Tajikistan and Kyrgyzstan) from the USSR in connection with the termination of its existence in accordance with the Agreement on the establishment of the CIS (Minsk, 08.12.1991).

Based on the study, it is proposed to recognize the following regulatory legal acts as invalid:

- Resolution of the USSR State Committee for Labor and the All-Union Central Council of Trade Unions Secretariat dated 07.09.1960 No. 1089/23 “On the approval of the regional coefficient to the wages of employees of logging, timber-floating, timber-handling enterprises and organizations, and chemical forestry enterprises located in the northern regions of the Kirov and Kostroma regions;

- Resolution of the USSR State Committee for Labor and the All-Union Central Council of Trade Unions Secretariat dated 03.10.1960 No. 1156/26 "On the approval of the regional coefficient to the wages of employees of individual enterprises of the machine-building and metalworking industry of the Ministry of Railways located in the regions of the Urals and Western Siberia"; etc. 
In the Strategy for the Spatial Development of the Russian Federation for the period up to 2025, approved by the order of the Government of the Russian Federation No. 207-r dated February 13, 2019, considerable attention is paid to the state regional policy, including the improvement of the socio-economic development of the northern and eastern regions, including the Arctic. in particular, the Northern Sea Route, as well as the Far East. Therefore, attracting the population to the northern and eastern regions of Russia has not lost its significance at the present time.

In this regard, it is proposed that basic guarantees and compensations for persons working and living in the Far North and equivalent areas, including the Arctic, be preserved for the near future, as provided in clause 6.2. Of the General Agreement for 2018-2020, but gradually improve them in accordance with the changing socio-economic conditions, first of all, an increase in the standard of living of the population, the creation of an urban (village) infrastructure, and an improvement in the transport accessibility of remote northern and arctic regions.

To improve the legislation on regional coefficients to the wages of workers in areas with unfavorable natural and climatic conditions for the population, it is necessary:

- to prepare new methodological approaches to determining the size of regional coefficients on the basis of the minimum (recovery) budget or the minimum consumer budget of an employee employed in moderate labor in normal working conditions, as well as a family of 4 people with two workers, including expenses for education of children, expenses for recreation, medical care, purchase of housing, etc. The sizes of regional coefficients are proposed to be established not only for the constituent entities of the Russian Federation, but also taking into account their zoning by natural and climatic zones within the constituent entity of the Russian Federation, for example, in the Krasnoyarsk Territory (4 zones), the Republic of Sakha (Yakutia) (4 zones), Khabarovsk Territory (3 zones), Irkutsk region (2 zones), etc.:

- to introduce the practice of establishing uniform regional coefficients for the wages of all employees of enterprises, organizations and institutions in the constituent entity of the Russian Federation or in municipal districts and urban districts within the constituent entity of the Russian Federation.

\section{References}

1. S. Allegretto, A. Dube, M. Reich, B. Zipperer, Credible Research Designs for Minimum Wage Studies (Institute for Research on Labor and Employment, 2013)

2. P. Bastos, N. Monteiro, Journal of Economics and Management Strategy, 20(4), 957 (2011)

3. D. Belman, P. Wolfson, What Does the Minimum Wage Do? (Kalamazoo, Upjohn Institute for Employment Research, 2014)

4. P. Belser, U. Rani, Minimum Wages and Inequality (Edward Elgar Publishing, Cheltenham, 2015)

5. V. Gimpelson,R. Kapelyushnikov, A. Lukyanova, Anna, Comparative Economic Studies 52(4), 611 (2010)

6. S. Kapelyuk, Economics of Transition 23(2), 389 (2015)

7. A. Lukiyanova, N. Vishnevskaya, Working papers by NRU Higher School of Economics, 90 (2015)

8. A. Muravyev, Europe-Asia Studies, 66(8), 1270 (2014) 